\title{
Severe iron deficiency anaemia following bariatric surgery
}

\author{
Robin George Manappallil \\ Consultant - Physician, Department of Medicine, National Hospital, Calicut, Kerala - 673009, India
}

The human body stores energy in the fat cells as triglycerides, which when needed gets released as free fatty acids. This physiologic system enables humans to withstand starvation for several months. But this system may get interrupted by genetic factors and sedentary lifestyle, leading to increase adipose energy stores and morbidity or mortality. Obesity is a chronic condition, which may be difficult to treat with therapeutic lifestyle modifications alone, that is diet and exercise. In such cases, bariatric surgery (BS) is an option to lose weight, in order to prevent serious health issues. However, nutritional deficiencies following this surgery have been of great concern. This case report is regarding a young lady who developed severe iron deficiency anaemia (IDA) within 6 months of BS despite taking nutritional supplements.

Key words: Obesity, Bariatric surgery, Iron deficiency anaemia, Nutritional deficiencies

\section{Access this article online}

Website:

http://nepjol.info/index.php/AJMS DOI: 10.3126/ajms.v7i4.14559

E-ISSN: 2091-0576

P-ISSN: 2467-9100

\section{INTRODUCTION}

Obesity is a state of excess adipose tissue deposition in the body, which has a direct link to mortality or morbidity. Body mass index (BMI), which is measured as weight/ height ${ }^{2}\left(\mathrm{~kg} / \mathrm{m}^{2}\right)$ is a widely used method to assess obesity. Large scale epidemiological studies have shown that cancer and cardiovascular morbidity tend to rise when BMI is $\geq 25 \mathrm{~kg} / \mathrm{m}^{2}$. Dietary modifications and regular physical exercise form the first step of therapy. However, in cases of morbid obesity (BMI $\geq 40 \mathrm{~kg} / \mathrm{m}^{2}$ ) or obese patients with comorbidities, surgical approach can be advised, as diet and exercise alone may be ineffective. One of the major drawbacks of BS is the development of nutritional deficiencies, that is, iron, vitamin B12, folate, protein and calcium. The patient being reported is a young lady who was on nutritional supplement following BS, but still developed severe IDA within 6 months of surgery.

\section{Case history}

A 40 year old lady, reporter, presented to Medicine OPD with complaints of palpitations on exertion, and extreme fatigue. There were no other associated symptoms. She had history of undergoing BS (laparoscopic sleeve gastrectomy) for obesity 6 months ago. She was taking nutritional supplements following the surgery. She was not on any regular medications. She had symptoms of acid reflux along with decreased appetite. She did not give any history of malena or hematochezia or menorrhagia.

On examination, she was moderately built, with BMI of $22 \mathrm{~kg} / \mathrm{m}^{2}$ (Her BMI was $38 \mathrm{~kg} / \mathrm{m}^{2}$ prior to BS). Her heart rate was 100 beats/minute, which was regular, blood pressure of $110 / 80 \mathrm{mmHg}$ and respiratory rate of 20 breaths/minute. She was afebrile. Her skin and conjunctiva were pale, tongue was bald and mildly swollen, and nails were brittle. Her systemic examinations were normal.

Her complete blood count showed severe anaemia with $\mathrm{Hb}$ of $4.9 \mathrm{~g} \%$ (12- 15), MCV $50.5 \mathrm{fL}$ (79-93), MCH $16.1 \mathrm{pg} / \mathrm{cell}$ (26-32) and MCHC $28.6 \mathrm{~g} \%$ (32-36). Her total counts, differential counts and platelets were normal. Peripheral smear showed microcytic hypochromic anaemia. Her iron profile revealed serum ferritin $4.7 \mathrm{ng} / \mathrm{ml}(10-290)$, serum iron $296 \mathrm{mcg} \%$ (50-170), total iron binding capacity $464 \mathrm{mcg} \%(250-450)$ and transferrin saturation of $67.12 \%(14-50)$. Her vitamin B12 and D3 
levels were $256 \mathrm{pg} / \mathrm{ml}$ (187-883) and $25 \mathrm{pg} / \mathrm{ml}(25-45)$ respectively. Her renal and liver functions, electrolytes, calcium and thyroid profile were normal. Stool microscopy was normal and stool occult blood was negative. ECG showed sinus tachycardia and ECHO heart was normal. Her ultrasound abdomen and chest radiography were also normal. Upper GI endoscopy revealed lax gastroesophageal junction, large hiatus hernia and diffuse gastritis, while her colonoscopy was normal. Based on the history, clinical features and investigations, a diagnosis of IDA following BS was considered.

She was transfused with 3 units of packed cell, following which her $\mathrm{Hb}$ picked up to $9.8 \mathrm{~g} \%$. She was also given parenteral iron injections. At the time of discharge, the patient was asymptomatic. She was advised iron, folic acid and vitamin B12, C and D supplements and rabeprazole. She was also asked to follow-up every 3 months with complete blood count, vitamin B12 and D reports.

\section{DISCUSSION}

According to the WHO, the percentage of obese people have been rising at a steady phase, posing a major health issue. ${ }^{1}$ Weight reduction methods, including diet and exercise, behavioural modifications and pharmacotherapy have not been successful in all cases. BS has been recognized as an effective method for weight reduction in morbid obesity. ${ }^{2}$ BS procedures are divided into restrictive, restrictive/malabsorptive and malabsorptive types. The procedures offered are adjustable gastric band (AGB), Roux-en-Y gastric bypass (RYGB), vertical sleeve gastrectomy (VSG) and biliopancreatic diversion with a duodenal switch (BPD-DS). The patient mentioned in this case report underwent VSG.

VSG, also known as laparoscopic sleeve gastrectomy, was introduced in 1988 as a part of BPD-DS. BPD-DS has restrictive and malabsorptive action, wherein the VSG provides the restrictive part. ${ }^{3}$ The American Society for Metabolic and Bariatric Surgery (ASMBS) recognized VSG as both a primary BS procedure, as well as the first stage in BPD-DS. ${ }^{4}$ In VSG, a major portion of the stomach along with the greater curvature is removed, retaining the pylorus. As a result, the digestion and absorption mechanism is not affected, compared to other types of BS. Since the stomach size is reduced, there is early satiety and reduced oral intake. Also there is increased intraluminal pressure which also causes early satiety. ${ }^{3}$ Ghrelin is an appetite-stimulating gut hormone produced mainly in the stomach. It also stimulates the release of growth hormone. In VSG, with the removal of large part of stomach, the ghrelin producing cells are eliminated. ${ }^{5}$
IDA is characterized by defect in haemoglobin synthesis. The red blood cells are small in size (microcytic) and contain less amount of haemoglobin (hypochromic). The patients with IDA present with fatigue, dizziness, dyspnoea, taste disturbances and restless leg syndrome. The commonly seen clinical features include pallor, brittle nails, angular stomatitis and glossitis. ${ }^{6}$ The concentration of haemoglobin is a direct indicator of anaemia. The diagnosis of IDA is confirmed by low serum ferritin levels along with low haemoglobin or haematocrit. ${ }^{7}$ Ferritin is an intracellular iron storage protein, and its levels indicate iron reserves. ${ }^{6}$ The levels of serum transferrin, an iron transport protein, rises when iron stores are low. ${ }^{8}$

Studies have shown that patients undergoing VSG are at risk of developing microcytic anaemia, pernicious anaemia and metabolic bone disorders due to iron, folate, vitamin B12 and D deficiencies. Following VSG, there is decrease in the gastric acid production leading to decrease in intrinsic factor, resulting in decreased iron and vitamin B12 absorption. Because the body storage of vitamin B12 is large compared to the daily requirements, the deficiency is noticed only after few years of surgery. Thiamine deficiency has also been reported in several cases. ${ }^{9-11}$ The ASMBS along with the American Association of Clinical Endocrinologists and the Obesity Society has outlined the nutritional recommendations in their 2013 update of the Clinical Practice Guidelines for the Perioperative Nutritional, Metabolic, and Nonsurgical Support of the Bariatric Surgery Patient. ${ }^{12}$

The patient being reported was an obese lady who underwent VSG for weight reduction and developed severe IDA due to insufficient nutritional supplement within just 6 months of surgery. This case indicates the possibility of developing severe nutritional deficiencies in a short period of time following BS and emphasises the need for proper nutritional education to these patients.

\section{REFERENCES}

1. Obesity and overweight. World Health Organization website. http://www.who.int/mediacentre/factsheets/fs311/en/index.html. Updated March 2013.

2. ASMBS position statement: bariatric surgery in class 1 obesity (BMI 30-35kg/m2). American Society for Metabolic \& Bariatric Surgery website. http://asmbs.org/2012/09/ bariatric-surgeryin-class-1-obesity-bmi-30-35-kgm2/. Updated September 7, 2012.

3. Saber AA, Elgamal MH and McLeod MK. Bariatric surgery: the past, present, and future. Obes Surg 2008; 18(1):121-128.

4. ASMBS Clinical Issues Committee. Updated position statement on sleeve gastrectomy as a bariatric procedure. Surg Obes Relat Dis 2012;8(3):e21-e26.

5. Papailiou J, Albanopoulos K, Toutouzas KG, Tsigris C, Nikiteas N 
and Zografos G. Morbid obesity and the sleeve gastrectomy: how does it work? Obes Surg 2010; 20(10):1448-1455.

6. Provan D. Mechanisms and management of iron deficiency anaemia. Br J Haematol 1999;105 Suppl 1:19-26.

7. Centers for Disease Control and Prevention. Recommendations to prevent and control iron deficiency in the United States. MMWR Morb Mortal Wkly Rep 1998;47(RR-3):1-29.

8. Wharton BA. Iron deficiency in children: detection and prevention. Br J Haematol 1999; 106(2):270-280.

9. Hakeam HA, O'Regan PJ, Salem AM, Bamehriz FY and Eldali AM. Impact of laparoscopic sleeve gastrectomy on iron indices: 1 year follow-up. Obes Surg 2009; 19(11):1491-1496.

10. Gehrer S, Kern B, Peters T, Christoffel-Courtin C and Peterli R.
Fewer nutrient deficiencies after laparoscopic sleeve gastrectomy (LSG) than after laparoscopic roux-y-gastric bypass (LRYGB): a prospective study. Obes Surg 2010; 20(4):447-453.

11. Capoccia D, Coccia F. Paradiso F, Abbatini F, Casella G, Basso N, et al. Laparoscopic gastric sleeve and micronutrients supplementation: Our experience. Journal of ObesityVolume 2012 (2012), Article ID 672162, 5 pages.

12. Mechanick JI, Youdim A, Jones DB, Garvey WT, Hurley DL, McMahon $M$, et al. Clinical practice guidelines for the perioperative nutritional, metabolic, and nonsurgical support of the bariatric patient-2013 update: cosponsored by American Association of Clinical Endocrinologists, the Obesity Society, and American Society for Metabolic \& Bariatric Surgery. Obesity (Silver Spring) 2013; 21 Suppl 01:S1-S27.

\section{Authors Contribution:}

RGM - Treating Physician, Author and Corresponding Author

Source of Support: Nil, Conflict of Interest: None declared. 